\title{
Regulator of G Protein Signaling 3 Modulates Wnt5b Calcium Dynamics and Somite Patterning
}

\author{
Christina M. Freisinger ${ }^{1}$, Rory A. Fisher ${ }^{2}$, Diane C. Slusarski ${ }^{1 *}$
}

1 Department of Biology, University of lowa, lowa City, lowa, United States of America, 2 Department of Pharmacology, University of lowa College of Medicine, lowa City, lowa, United States of America

\begin{abstract}
Vertebrate development requires communication among cells of the embryo in order to define the body axis, and the Wntsignaling network plays a key role in axis formation as well as in a vast array of other cellular processes. One arm of the Wntsignaling network, the non-canonical Wnt pathway, mediates intracellular calcium release via activation of heterotrimeric $G$ proteins. Regulator of $\mathrm{G}$ protein Signaling (RGS) proteins can accelerate inactivation of $\mathrm{G}$ proteins by acting as $\mathrm{G}$ protein GTPase-activating proteins (GAPs), however, the possible role of RGS proteins in non-canonical Wnt signaling and development is not known. Here, we identify rgs3 as having an overlapping expression pattern with wnt5b in zebrafish and reveal that individual knockdown of either rgs3 or wnt5b gene function produces similar somite patterning defects. Additionally, we describe endogenous calcium release dynamics in developing zebrafish somites and determine that both rgs3 and wnt5b function are required for appropriate frequency and amplitude of calcium release activity. Using rescue of gene knockdown and in vivo calcium imaging assays, we demonstrate that the activity of Rgs 3 requires its ability to interact with $\mathrm{G} \alpha$ subunits and function as a G protein GAP. Thus, Rgs3 function is necessary for appropriate frequency and amplitude of calcium release during somitogenesis and is downstream of Wnt5 activity. These results provide the first evidence for an essential developmental role of RGS proteins in modulating the duration of non-canonical Wnt signaling.
\end{abstract}

Citation: Freisinger CM, Fisher RA, Slusarski DC (2010) Regulator of G Protein Signaling 3 Modulates Wnt5b Calcium Dynamics and Somite Patterning. PLoS Genet 6(7): e1001020. doi:10.1371/journal.pgen.1001020

Editor: Henrik G. Dohlman, University of North Carolina, United States of America

Received January 5, 2010; Accepted June 7, 2010; Published July 8, 2010

Copyright: (c) 2010 Freisinger et al. This is an open-access article distributed under the terms of the Creative Commons Attribution License, which permits unrestricted use, distribution, and reproduction in any medium, provided the original author and source are credited.

Funding: This work was funded by an NIH grant to DCS (www.nih.gov) and an AHA predoctoral fellowship to CMF (www.americanheart.org). The funders had no role in study design, data collection and analysis, decision to publish, or preparation of the manuscript.

Competing Interests: The authors have declared that no competing interests exist.

*E-mail: diane-slusarski@uiowa.edu

\section{Introduction}

The Wnt signaling network is classified into $\beta$-catenindependent and $\beta$-catenin-independent pathways [1-3]. $\beta$-catenin-dependent Wnt signaling acts through the stabilization of $\beta$ catenin and subsequent transcriptional activation of $\beta$-catenin targets [4], whereas $\beta$-catenin-independent Wnt signaling influences cell polarity (known as Planar Cell Polarity or PCP in Drosophila). $\beta$-catenin-independent Wnt signaling has also been shown to lead to calcium $\left(\mathrm{Ca}^{2+}\right)$ release as well as activation of Rac, Rho and other cytoskeletal components in vertebrates $[5,6]$. In zebrafish, Wnt-5 and -11 function in $\mathrm{Wnt} / \mathrm{Ca}^{2+}$ signaling $[7,8]$. Wntll is enriched in the anterior and mutants show anterior extension and eye fusion defects, while $\mathrm{Wnt} 5 \mathrm{~b}$ is enriched in the posterior and mutants show altered cell movements during gastrulation, often resulting in convergence extension and somite defects [9-11].

Zebrafish embryos demonstrate $\mathrm{Ca}^{2+}$ release dynamics during epiboly, gastrulation, convergent extension and organogenesis [12-21]. Two distinct types of $\mathrm{Ca}^{2+}$ release events, aperiodic transient fluxes found mainly in the enveloping layer and dorsal forerunner cells $[17,18,22,23]$ and sustained increases in $\mathrm{Ca}^{2+}$ levels in the deep cell layer and yolk syncytial layer [24,25], have been described. We have shown that early $\mathrm{Ca}^{2+}$ transients are, in part, modulated by Wnt5 $[15,26]$. The zebrafish wont $5 b$ genetic mutant (pipetail) shows reduced $\mathrm{Ca}^{2+}$ release [24] and the ventralized maternal effect mutant hecate shows ectopic $\mathrm{Ca}^{2+}$ release [18]. Moreover, inhibition of $\mathrm{Ca}^{2+}$ release results in alteration of dorsal ventral patterning, cell movement and leftright patterning $[17,26]$. These observations suggest that the kinetics of $\mathrm{Ca}^{2+}$ release, both transient and sustained, translate into distinct developmental outputs [16].

Wnts interact with receptors of the Frizzled $(\mathrm{Fz})$ family [27] and due to structural similarities to $G$ protein coupled receptors (GPCR), Fz receptors are hypothesized to stimulate heterotrimeric $\mathrm{G}$ protein activation [28-30]. We have shown previously that Wnt proteins work though specific $\mathrm{Fz}$ homologues to activate $\mathrm{G}$ proteins and to modulate $\mathrm{Ca}^{2+}$ release in zebrafish embryos [15,22,26,31]. Moreover, in Drosophila, Wnt target genes have been shown to be upregulated when G $\alpha_{0}$ is over-expressed and constitutively active $\mathrm{G} \alpha$ o is sufficient to restore Wnt signaling in the absence of $\mathrm{Fz}$ activity [32]. In addition, epistasis experiments support that $\mathrm{G}$ proteins function downstream of $\mathrm{Fz}$ and upstream of Disheveled (Dvl) [32].

$\mathrm{G}$ protein signaling is regulated by the lifetime of active $\mathrm{G} \alpha$ and $\beta \gamma$ subunits. Activated $\mathrm{G} \alpha$ subunits have an intrinsic GTPase activity that converts the GTP-bound conformation to the G $\alpha$ GDP bound conformation allowing reassembly with G $\beta \gamma$ subunits to form the inactive $G \alpha \beta \gamma$ heterotrimer [33]. Regulator of $G$ protein Signaling (RGS) proteins have been shown to influence the duration of $G$ protein signaling [34-37]. RGS proteins share a conserved RGS domain of 130 amino acids that binds to activated $\mathrm{G} \alpha$ subunits and accelerates their rates of GTP hydrolysis by up to 1000-fold [38-40]. By functioning as GTPase-activating proteins 


\section{Author Summary}

Vertebrate development requires communication among cells in order to define the body axis (front/back, head/tail, or left/right). Secreted factors such as Wnts play key roles in a vast array of cellular processes, including patterning of the body axis. One arm of the Wnt-signaling network, the non-canonical pathway, mediates intracellular calcium release via activation of heterotrimeric $G$ proteins. Regulator of $G$ protein Signaling (RGS) proteins can accelerate inactivation of $G$ proteins by acting as $G$ protein GAPs and are uniquely situated to control the amplitude of a Wnt signal. Here, we combine cellular, molecular, and genetic analyses with high resolution calcium imaging to identify a role for RGS modulation of Wnt-mediated calcium release dynamics and developmental patterning events. We find that loss of rgs3 gene function produced body patterning defects like those observed with loss of wnt5b gene function. Analysis of endogenous calcium release dynamics in developing zebrafish revealed that both rgs3 and wnt5b are required for appropriate frequency and amplitude of calcium release. Our results provide new evidence that a member of the RGS protein family is essential for modulating the non-canonical Wnt network to assure normal tissue patterning during development.

(GAPs) for G proteins, RGS proteins are uniquely situated to modulate the intensity and duration of Wnt signaling. However, no studies have ascertained the possible importance of RGS proteins in non-canonical Wnt signaling or whether changes in frequency and or amplitude of signaling result in biological defects.

To investigate potential roles of RGS proteins in vertebrate development, we utilize gene knockdown in zebrafish. We focus on rgs3, which was identified in an expression screen in zebrafish [41]. We find that $r g s 3$ is expressed in overlapping and adjacent domains with wnt5b at multiple stages of zebrafish development. Morpholino knockdown of $\operatorname{rgs}_{3} 3$ in zebrafish embryos causes convergence and extension $(\mathrm{CE})$ defects that resemble phenotypes observed in the wnt5b genetic mutant, pipetail [42]. To this end, we have identified a genetic interaction between $\operatorname{rgs} 3$ and wnt $5 b$. Additionally, we describe endogenous $\mathrm{Ca}^{2+}$ release dynamics during somite stages and show that Rgs3 and Wnt5b impact the frequency of $\mathrm{Ca}^{2+}$ release. Moreover, we show that Rgs3 modulates the extent and duration of Wnt5b induced $\mathrm{Ca}^{2+}$ activity. Functional analyses show that both the rescue of the rgs 3 knockdown defect and impact on Wnt5-induced $\mathrm{Ca}^{2+}$ release requires a key asparagine in the RGS domain of Rgs3 necessary for $\mathrm{G} \alpha$ binding and acceleration of its GTPase activity. This research identifies a link between Wnt5b signaling and Rgs3 activity relative to the frequency of $\mathrm{Ca}^{2+}$ release, thus revealing obligatory roles for RGS proteins in vertebrate development in the context of the whole animal. Our results also demonstrate that the biological outcome of Wnt signaling depends greatly upon regulating the duration of its signal, as shown here with Rgs3.

\section{Results}

\section{Expression of $r g s 3$}

Zebrafish rgs3 was identified in an expression screen during early somitogenesis stages [41] and is poised to interact with the Wnt signaling network. Utilizing Reverse Transcriptase Polymerase Chain Reaction (RT-PCR), we determined that rgs3 expression begins during the blastula period shortly after zygotic transcription initiates (2.5-5 hours post fertilization, hpf), and persists through the segmentation period (10-24hpf) (Figure 1A). Whole Mount In Situ Hybridization (WMISH) demonstrated ubiquitous rgs3 expression during epiboly and gastrulation stages. During somite stages (10-20 hpf), rgs3 expression resolves in the somites, tailbud, and brain (Figure 1B-1G), with discrete rgs 3 expression in the midbrain/hindbrain boundary as demonstrated by overlap with

A
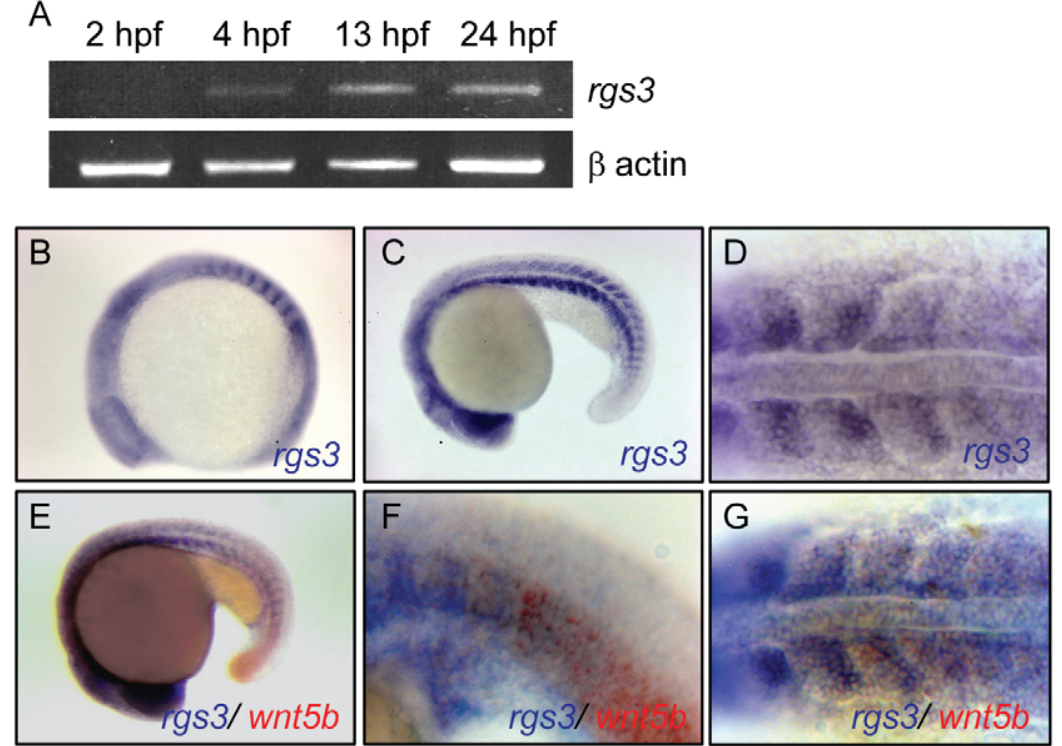

Figure 1. Temporal and spatial expression of rgs3 throughout zebrafish development. RT-PCR was used to determine the temporal expression of rgs3 from $0 \mathrm{hpf}$ to $24 \mathrm{hpf}(\mathrm{A})$. Whole Mount In Situ Hybridization was utilized to determine the spatial expression of rgs3 in $12 \mathrm{hpf}$ (B) and $20 \mathrm{hpf}(\mathrm{C}, \mathrm{D})$ wild type embryos. rgs3 and wnt5b double label in situ in $18 \mathrm{hpf}$ embryos $(\mathrm{E}-\mathrm{G})$. Lateral $(\mathrm{B}, \mathrm{C}, \mathrm{E}, \mathrm{F})$ and dorsal $(\mathrm{D}, \mathrm{G})$ views illustrate that rgs3 is expressed in the developing somites (B-D) and posterior tail (C). At $18 \mathrm{hpf}$ rgs3 expression is enriched in the posterior (caudal) portion of the developing somites (D). Co-localization of $w n t 5 b$ and rgs3 was determined by double label WMISH with wnt5b (red) and rgs3 (blue) showing overlapping expression domains in the developing tail and somites $(E-G)$. Sense probes (negative control) gave no specific hybridization signal. doi:10.1371/journal.pgen.1001020.g001 
the molecular marker engrailed 1 (eng 1 ) at $28 \mathrm{hpf}$ (Figure S1F), and enriched rgs3 expression in the posterior (caudal) portion of developing somites (Figure 1D). rgs3 and wnt5b show both overlapping and adjacent expression domains in the somites and in the posterior tailbud (Figure 1E-1G and Figure S1A, S1B, S1C, $\mathrm{S} 1 \mathrm{D})$. rgs 3 expression is enriched around the Kupffer's vesicle (Figure S1C), a ciliated organ in the zebrafish embryo that has been shown to influence left-right patterning, yet rgs3 does not appear to be required for organ laterality (data not shown). As Wnt5b is a secreted ligand, the proximity of $r g s 3$ to wnt $5 b$ producing cells suggests that Rgs3 may function in modulating Wnt5b signaling.

\section{Rgs3 is sufficient to suppress Wnt5b-induced $\mathrm{Ca}^{2+}$ dynamics}

In zebrafish, went $5 b$ induces increased $\mathrm{Ca}^{2+}$ release during the blastula stage in a $\mathrm{G}$ protein dependent manner $[15,22,26]$. To determine if $r g s 3$ over-expression is sufficient to negatively regulate Wnt5b signaling (Figure 2A), we tested the impact of $\operatorname{rgs}_{3} 3$ on $w$ t $5 \mathrm{~b}$ induced $\mathrm{Ca}^{2+}$ release. In vivo imaging in blastula stage embryos is

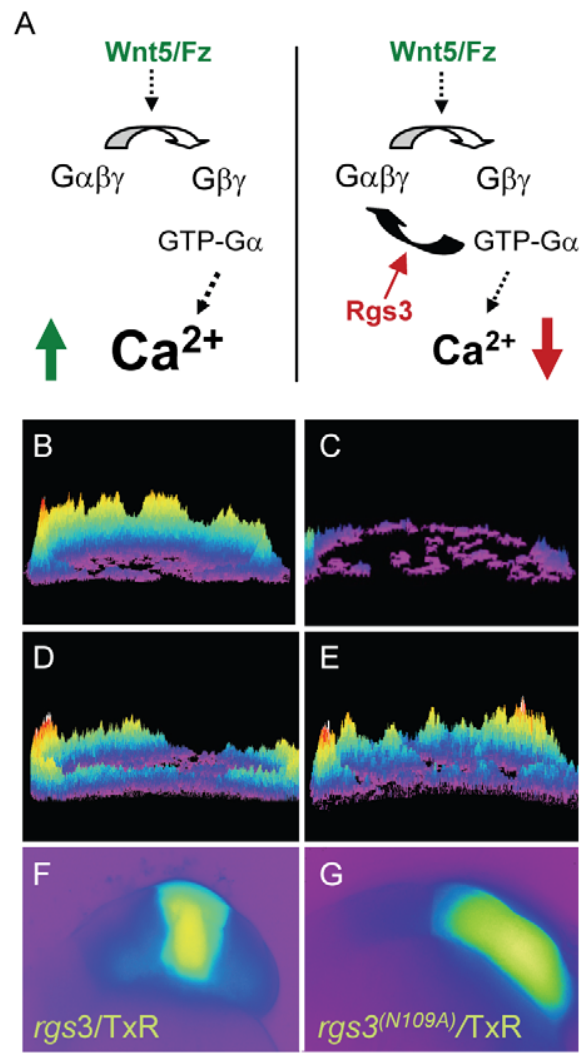

Figure 2. rgs 3 inhibits wnt5b-induced $\mathrm{Ca}^{2+}$ dynamics. Schematic representation illustrating that $W n t 5 b$ overexpression results in intracellular calcium release in a $G$ protein dependent manner $(A$, left side) and the predicted negative effect overexpression of Rgs 3 will have on the Wnt/calcium pathway (A, right side). Representative $\mathrm{Ca}^{2+}$ release profiles (composite image) of wnt5-overexpressing $(B, D, E)$ and wt $(C)$ blastula stage zebrafish embryos. (B-E) are composites of fura-2 ratiometric imaging time course showing total calcium release activity as peaks and colors mapped topographically. $\mathrm{Ca}^{2+}$ release profile of an embryo uniformly expressing wnt5b (B). Wt $\mathrm{Ca}^{2+}$ release profile (C). wnt5b expressing embryo with localized TxR/rgs3 (D) or Txr/rgs $3^{\mathrm{N} 109 \mathrm{~A}}$ (E). Corresponding fluorescent images illustrate the location of TxR/rgs3 (F) and TxR/rgs $3^{\text {N109A }}(\mathrm{G})$.

doi:10.1371/journal.pgen.1001020.g002 accomplished with the $\mathrm{Ca}^{2+}$ sensor Fura-2. Upon binding $\mathrm{Ca}^{2+}$, Fura-2 exhibits an absorption shift that can be determined by collection at two wavelengths $\left(340 \mathrm{~nm}, \mathrm{Ca}^{2+}\right.$-saturated and $380 \mathrm{~nm}$, $\mathrm{Ca}^{2+}$-free). A ratio image is derived as the quotient of the $340-\mathrm{nm}$ image divided by the 380 -nm image on a pixel-by-pixel basis, and provides spatial and temporal measurement of $\mathrm{Ca}^{2+}$ dynamics. $\mathrm{Ca}^{2+}$ release activity was monitored over a 75 minute time course during the blastula stage. Sequential ratiometric images were analyzed by a subtractive algorithm to identify changes in $\mathrm{Ca}^{2+}$ release activity (transients) over time as well as the location of the activity as described previously [13,43-45]. Transients identified during the time course are presented as a composite image with location of $\mathrm{Ca}^{2+}$ release mapped on the embryo. The number of $\mathrm{Ca}^{2+}$ transients during the cellular blastoderm stage is represented by height of the peaks and color coded where purple is low and yellow/red is high number of events. The composite image of a wild-type (wt) embryo during the blastula stage indicates endogenous $\mathrm{Ca}^{2+}$ levels throughout the embryo (Figure 2C) compared to those observed during increased $\mathrm{Ca}^{2+}$ release in an embryo injected with wnt5b (Figure 2B). Co-injection of $r g s 3$ with dextran-conjugated Texas Red $(\mathrm{T} x \mathrm{R})$ lineage tracer into a subset of cells in embryos uniformly expressing wnt5b co-mixed with Fura-2 supports that $r g s 3$ is sufficient to suppress $w n t 5 b$ induced $\mathrm{Ca}^{2+}$ release as demonstrated by the reduction of $\mathrm{Ca}^{2+}$ levels (Figure 2D) in the $\operatorname{rgs}_{3} / \mathrm{TxR}$ positive region (Figure 2F).

We next investigated if Rgs3 suppression of wnt5b induced $\mathrm{Ca}^{2+}$ release requires GAP activity. A conserved asparagine within the RGS domain of RGS proteins is necessary for GAP activity for $\mathrm{G} \alpha$ subunits [46-48]. Substitution of this key asparagine $(\mathbf{N})$ with Alanine (A) results in a loss of the GAP activity of RGS proteins towards $\mathrm{G} \alpha$ subunits in culture cells $[46,48]$. To elucidate the role of the GAP function of Rgs3, we created an $\mathrm{N}$ to A mutation in zebrafish $r g s 3\left(r g s 3^{\mathrm{N} 109 \mathrm{~A}}\right)$ (Figure $\left.3 \mathrm{~A}\right)$. We evaluated the impact of rgs $3^{\mathrm{N} 109 \mathrm{~A}}$ expression on Wnt5b induced $\mathrm{Ca}^{2+}$ release. Unlike rgs3, the $r g s 3^{\mathrm{N} 109 \mathrm{~A}}$ is unable to suppress wnt5b induced $\mathrm{Ca}^{2+}$ release (Figure 2E) as demonstrated by no change in the $\mathrm{Ca}^{2+}$ activity in the $r g s 3^{\mathrm{N} 109 \mathrm{~A}} / \mathrm{TxR}$ positive region of embryos (Figure $2 \mathrm{G}$ ). To rule out the possibility that lack of suppression by $\operatorname{Rgs}^{\mathrm{N} 109 \mathrm{~A}}$ was due to differences in its expression or localization compared to Rgs3, we generated and expressed N-terminal myc-tagged rgs3 and $r g s 3^{\mathrm{N} 109 \mathrm{~A}}$ constructs in embryos. Western analysis reveals robust and comparable expression of Rgs 3 and $\operatorname{Rgs} 3^{\mathrm{N} 109 \mathrm{~A}}$ at the time of $\mathrm{Ca}^{2+}$ imaging as well as through 24hpf (Figure 3B). Immunostaining for anti-myc in epiboly stage embryos also indicates that both proteins localize to the membrane and cytoplasm (Data not shown). Together these data strongly indicate that $r g s 3$ is sufficient to inhibit wnt5b-induced $\mathrm{Ca}^{2+}$ signaling and that this action requires the GAP activity of Rgs3.

\section{Endogenous requirement for rgs3 during embryogenesis}

Since Rgs3 is sufficient to modulate Wnt5 activity in an overexpression assay, we next evaluated the necessary role of rgs3 during development. To knockdown Rgs3, we utilized antisense morpholino oligonucleotides (MO) [49]. Three separate MOs were designed to bind rgs3 5'UTR (MO and $\mathrm{MOb}$ ) or splice junction (SA) (Figure 3A). All MOs designed to knockdown Rgs3 produced similar defects. Control-injected embryos at $28 \mathrm{hpf}$ are fully extended with a characteristic anterior-posterior (A-P) length (Figure 3C). In contrast, rgs3 MO-injected embryos have shorter A-P extension and a kinked tail (Figure 3D) reminiscent of defects observed in the wont5b (pipetail) genetic mutant [42]. Zebrafish somites develop sequentially anterior to posterior and form a distinct chevron shape [50] (Figure 3E). rgs3 morphants display tighter packed and rounded somites (Figure 3F). To evaluate 
A

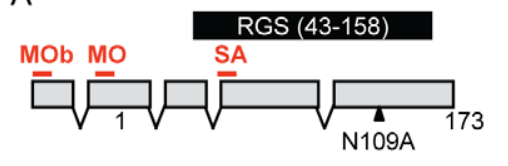

B

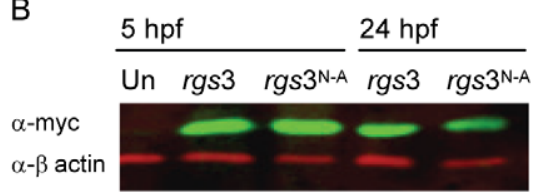

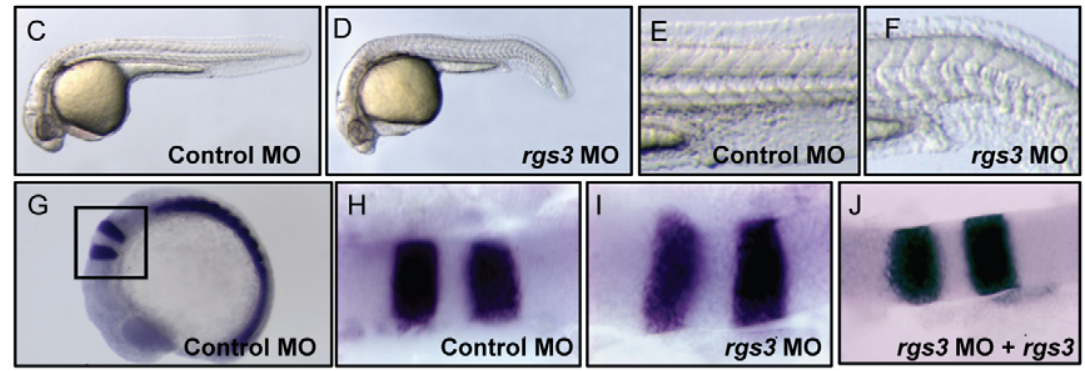
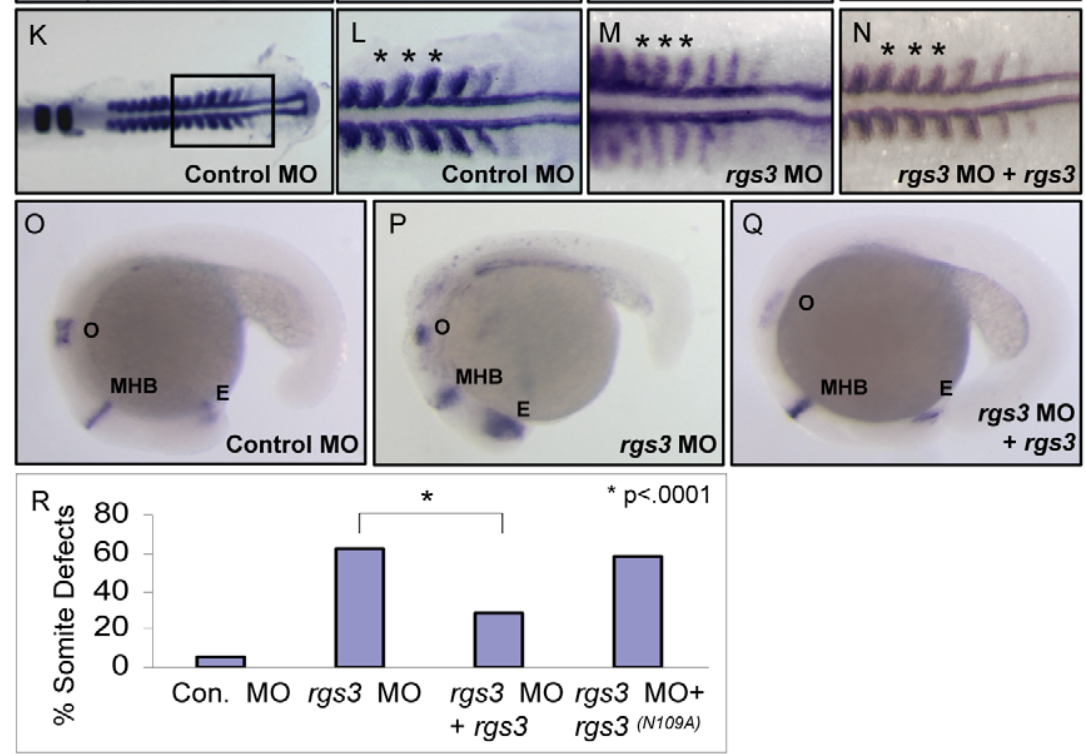

Figure 3. rgs 3 morphant phenotypes and functional rescue. Schematic of zebrafish rgs $3 \mathrm{mRNA} /$ protein composite (A). Numbers refer to the amino acid number of the encoded Rgs 3 protein, while the locations of morpholino binding sites employed in later experiments are indicated by red lines above the transcript. $\mathrm{MO}=\operatorname{rgs} 3 \mathrm{MO}, \mathrm{MOb}=\mathrm{rgs} 3 \mathrm{MOb}$ and $\mathrm{SA}=\mathrm{rgs} 3 \mathrm{MOsa}$. The RGS domain of Rgs3, amino acids $43-158$, is highlighted by the black box (A). Western analysis demonstrates that myc-tagged rgs 3 and rgs $3^{\mathrm{N} 109 \mathrm{~A}}$ proteins are detectable from 5 hpf to $24 \mathrm{hpf}(\mathrm{B})$. Antisense morpholino-mediated gene knockdown of rgs3 results in embryonic defects. Lateral views of 28 hpf wild-type (C,E) and rgs3 MO injected (D,F) embryos illustrate that $r g s 3$ morphants have a reduced body length (D) and altered somite formation (F). rgs3 was co-injected with rgs3 $\mathrm{MO}$ to monitor rescue of gene knockdown. The molecular markers krox20, myoD and pax2 were used to evaluate rgs3 morphant rescue (G-Q). krox 20 labels rhombomeres 3 and 5, myoD labels the developing somites and adaxial cells while, pax2 labels the otic vesicle (o), midbrain-hindbrain boundary $(\mathrm{MHB})$ and eye (E). Lateral (G and $\mathrm{O}-\mathrm{Q})$ and dorsal $(\mathrm{H}-\mathrm{N})$ views, anterior to the right, of $15 \mathrm{hpf}(\mathrm{G}-\mathrm{N})$ and 20 hpf (O-Q) wt embryos injected with Control $\mathrm{MO}(\mathrm{G}, \mathrm{H}, \mathrm{K}, \mathrm{L}, \mathrm{O})$, rgs3 $\mathrm{MO}(\mathrm{I}, \mathrm{M}, \mathrm{P})$ and rgs3 $\mathrm{MO}+\mathrm{rgs} 3(\mathrm{~J}, \mathrm{~N}, \mathrm{Q})$. Boxed regions in $\mathrm{G}$ and $\mathrm{K}$ represent the areas magnified in $\mathrm{H}-\mathrm{J}$ and $\mathrm{L}-\mathrm{N}$ respectively. Asterisks indicate the spacing and width of three representative somites $(\mathrm{L}-\mathrm{N})$. krox 20, myoD and pax2 expression patterns indicate that rgs 3 is able to suppress the morpholino-induced defect $(\mathrm{J}, \mathrm{N}, \mathrm{Q})$. For structural functional analyses, rgs $3^{\mathrm{N} 109 \mathrm{~A}}$ was evaluated for rescue of knockdown. Morphological analyses reveals that $r g s 3$ is able to suppress the MO induced defect $(\mathrm{R})$ while, $r g s 3^{(\mathrm{N} 109 \mathrm{~A})}$ is unable to suppress the MO induced defect $(\mathrm{R})$. doi:10.1371/journal.pgen.1001020.g003

anterior-posterior extension alterations at an earlier developmental stage $(15 \mathrm{hpf})$, molecular markers were used. Control-injected embryos have a characteristic spacing of krox20 expression in the hindbrain rhombomeres 3 and 5, as well as regular spaced blocks of myoD expression in the developing somites flanking the midline (Figure $3 \mathrm{G}-3 \mathrm{H}$ and $3 \mathrm{~K}-3 \mathrm{~L}$ ). In contrast, krox20 and myoD expression in $r g s 3$ morphants reveal a failure of cells to converge on the midline resulting in a lateral expansion of the rhombomeres and somites (Figure 3I and 3M). Additionally, rgs3 morphants fail to extend along the anterior-posterior (A-P) axis leading to closer spaced myoD (Figure 3M, asterisks). The A-P extension defects were further confirmed with pax2, a marker expressed in the anterior retina, midbrain/hindbrain, and otic vesicle of $18 \mathrm{hpf}$ embryos (Figure 3O). rgs 3 morphants display compression of these regions along the A-P axis (Figure $3 \mathrm{P}$ ). Together these data strongly indicate that $r g s 3$ is required for normal anterior-posterior axis extension.

The specificity of the rgs3 knockdown as well as structural functional analyses were determined by RNA co-injection experiments. Injection of control 5bp mismatch $\mathrm{MO}$ resulted in negligible defects compared to rgs 3 MO which induced morphological somite defects (Figure 3R). Co-injection of rgs3 MO with rgs3 RNA suppressed the MO-induced defects evaluated by molecular markers krox20 (Figure 3J), myoD (Figure 3N, asterisks) and pax2 (Figure 3Q). Moreover, wild-type rgs3 RNA leads to significant suppression of MO-induced defects (Figure 3R and 
Table S1). In contrast, $r g s 3^{\mathrm{N} 109 \mathrm{~A}}$ mutant RNA does not suppress the MO-induced defect (Figure 3R and Table S1). These results demonstrate that Rgs3 GAP activity is required for its developmental functions.

\section{rgs3 function is necessary for endogenous $\mathrm{Ca}^{2+}$ dynamics in somites}

The functional requirement of rgs3 during anterior-posterior axis extension and the finding that over-expression of rgs 3 is sufficient to inhibit wot5b-induced $\mathrm{Ca}^{2+}$ signaling, raised the possibility that $\operatorname{rgs}_{3} 3$ may negatively modulate $\mathrm{Ca}^{2+}$ release dynamics during somitogenesis. In fact, $\mathrm{Ca}^{2+}$ signals along the trunk of zebrafish embryos during somitogenesis have been described using the bioluminescent $\mathrm{Ca}^{2+}$ reporter $\mathrm{R}$-aequorin $[12,51,52]$. In order to compare changes in $\mathrm{Ca}^{2+}$ release dynamics upon rgs3 manipulation, we performed a detailed analysis of endogenous $\mathrm{Ca}^{2+}$ release in tissues that express both went $5 b$ and rgs3. To this end, we utilized Fura-2 imaging to monitor $\mathrm{Ca}^{2+}$ activity with a focus on the developing somites and tailbud in either a dorsal (Figure 4A) or a lateral (Figure S2A) orientation. The pseudocolored ratio image provides a spatial and temporal measurement of $\mathrm{Ca}^{2+}$ dynamics with low $\mathrm{Ca}^{2+}$ represented by blue and high $\mathrm{Ca}^{2+}$ represented by yellow/red. Representative pseudocolored ratio images from a time-lapse series of $\mathrm{Ca}^{2+}$ measurements (Video S1), spanning the 3-13 somite stages are shown (Figure 4B-4E). The notochord and forming somites can be identified in the grayscale fluorescence images (Figure $4 \mathrm{~B}^{\prime}-4 \mathrm{E}^{\prime}$ ). Overlay of grayscale and ratio images illustrate the regions of increased $\mathrm{Ca}^{2+}$ levels relative to morphology (Figure $4 \mathrm{~B}^{\prime \prime}-4 \mathrm{E}^{\prime \prime}$ ).

$\mathrm{Ca}^{2+}$ release activity during somitogenesis is dynamic with sustained $\mathrm{Ca}^{2+}$ levels in the presomitic mesoderm, lateral to the somite forming region and flanking the midline/notochord (Figure $4 \mathrm{~B}^{\prime \prime}-4 \mathrm{E}^{\prime \prime}$ ). As somitogenesis proceeds, sustained $\mathrm{Ca}^{2+}$ levels appear distinctly between the somites (Figure 4C"-4E", arrowheads). In addition, we observe localized short-lived increases in $\mathrm{Ca}^{2+}$ release (referred to as transients). To demonstrate a transient, a region of interest (ROI) is noted by dashed circle (Figure $5 \mathrm{~A}-$ $5 \mathrm{C})$. In the ROI, an increase in $\mathrm{Ca}^{2+}$ is observed from time 0 s to time $15 \mathrm{~s}$ and the local increase subsides by time $30 \mathrm{~s}$. Since $\operatorname{rgs}_{s} 3$ may function to influence the frequency of $\mathrm{Ca}^{2+}$ release, we determined the number of transients as a function of developmental age (Figure 5D). In wt embryos, we observe an average of $5.3 \mathrm{Ca}^{2+}$ transients per hour $(\mathrm{n}=3)$ (Figure 5E). A similar frequency is found when analyzing the data from a lateral view (Figure S2B, S2C, S2D, and S2K).

Having defined endogenous $\mathrm{Ca}^{2+}$ release dynamics during somitogenesis, we next determined the impact of $r g s 3$ knockdown. From the development of somite 6 to somite 12, rgs 3 morphants have statistically more $\mathrm{Ca}^{2+}$ transients, with an average of 21.7 per hour $(\mathrm{n}=3)$, when compared to wt embryos (Figure 5D and 5E). rgs3 morphants have sustained $\mathrm{Ca}^{2+}$ levels in the lateral regions similar to wt. However the dynamics within the somite region frequently show
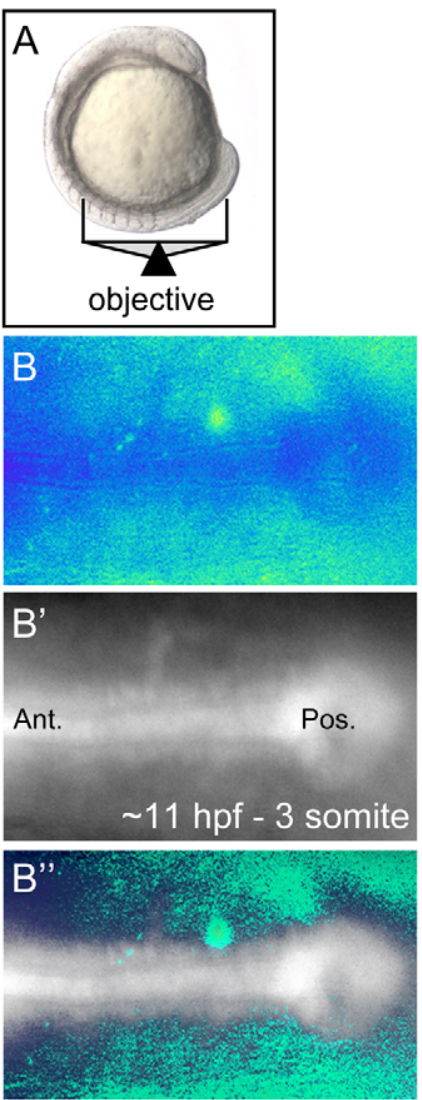
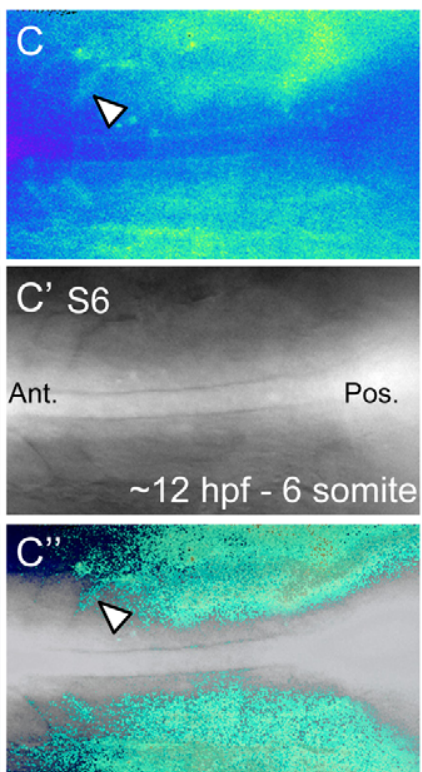
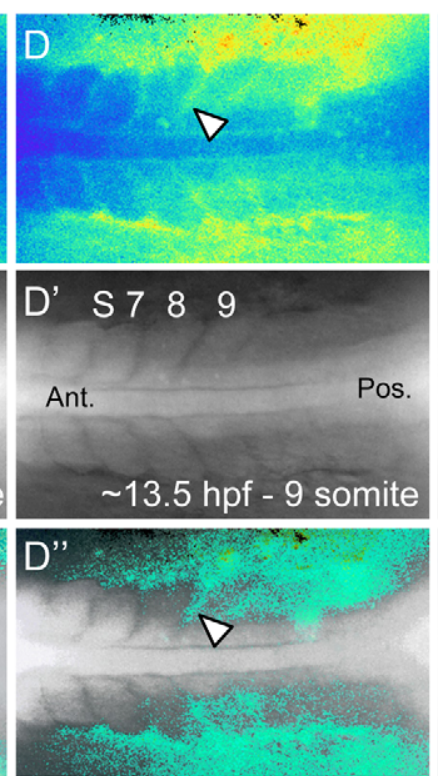
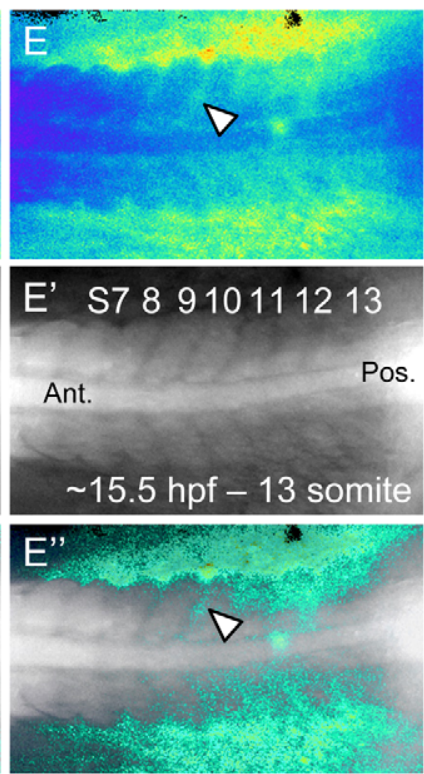

Figure 4. $\mathrm{Ca}^{2+}$ dynamics during zebrafish somitogenesis. Illustration of the position of a 10 somite stage (14 hpf) zebrafish embryo relative to the objective during $\mathrm{Ca}^{2+}$ imaging (A). Representative ratio images, pseudocolored with low ratio (low $\mathrm{Ca}^{2+}$ ) represented by blue and high ratio (high $\left(\mathrm{Ca}^{2+}\right)$ represented by yellow/red, of 3, 6, 9 and 13 somite stage embryos (B-E respectively). The forming somites and notochord can be identified by the grayscale fluorescence images $\left(\mathrm{B}^{\prime}-\mathrm{E}^{\prime}\right)$. Overlay of grayscale and ratio images illustrate the regions of $\mathrm{Ca}^{2+}$ release activity relative to morphology $\left(\mathrm{B}^{\prime \prime}-\mathrm{E}^{\prime \prime}\right)$. Arrowheads indicate areas of sustained $\mathrm{Ca}^{2+}$ activity between forming somites. Ant. = Anterior, Pos. $=$ Posterior and $\mathrm{S}=$ somite number. doi:10.1371/journal.pgen.1001020.g004 

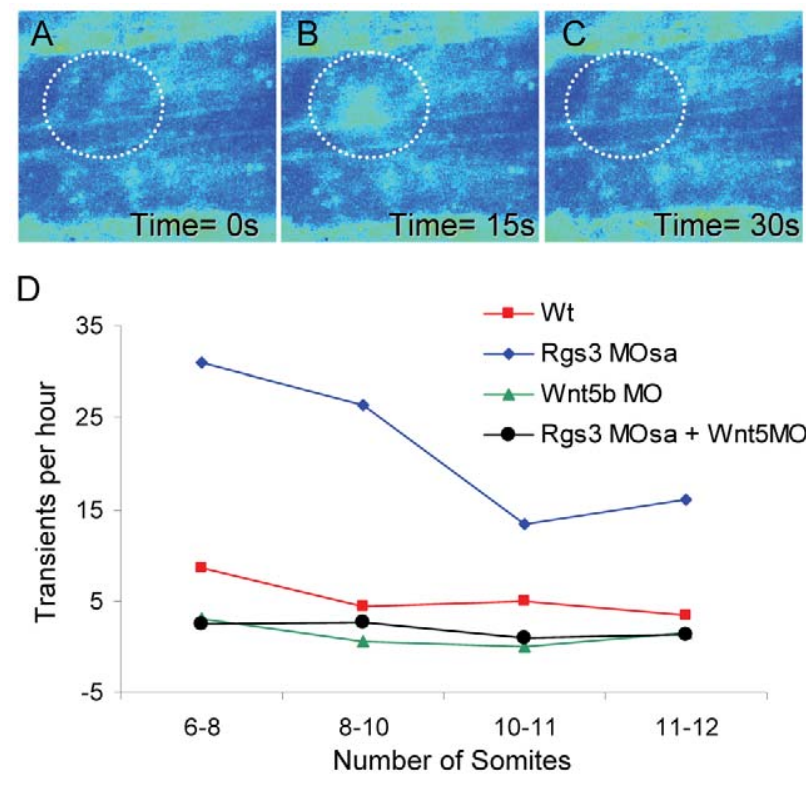

\begin{tabular}{|l|c|}
\hline E Avg. transients/hr \\
\hline $\mathrm{Wt}$ & 5.3 \\
\hline rgs3 MOsa & $21.7^{*}$ \\
\hline $\begin{array}{l}\text { wnt5b MO } \\
\text { rgs3 MOsa } \\
+ \text { wnt5b MO }\end{array}$ & $1.3^{*}$ \\
\hline $\begin{array}{l}\text { rgs3 MOsa } \\
+ \text { rgs3 }\end{array}$ & $\begin{array}{c}2.9 \\
{ }^{*} \mathrm{p}<.01\end{array}$ \\
\hline
\end{tabular}
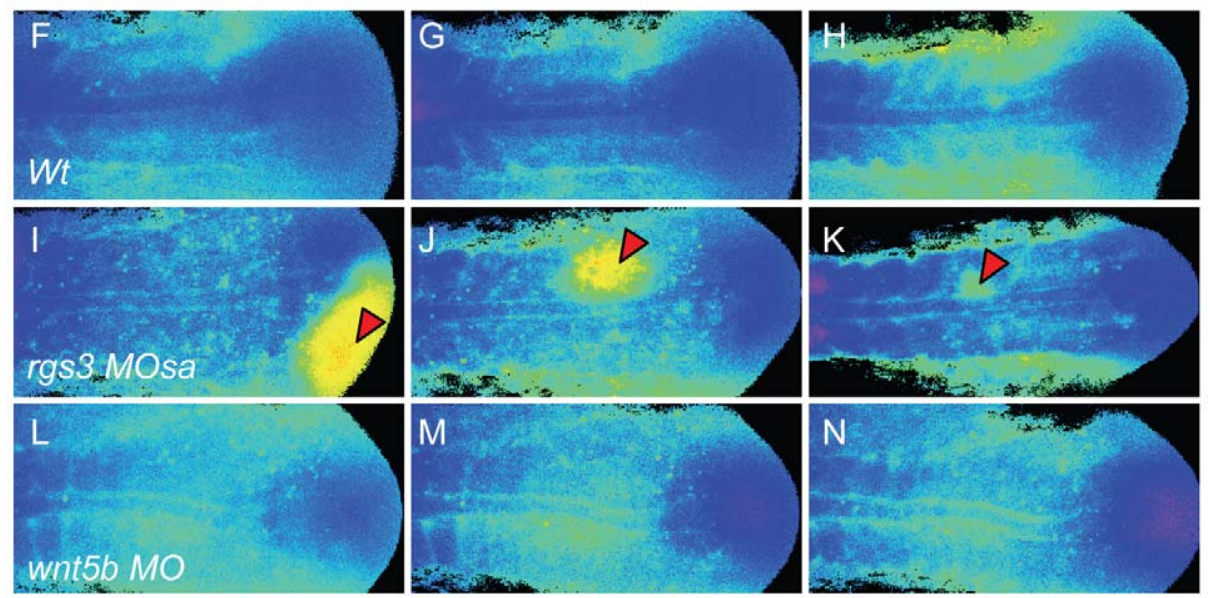

Figure 5. rgs3 impacts segmentation stage $\mathbf{C a}^{2+}$ dynamics. Zebrafish embryos injected with Fura-2 were oriented in a dorsal posterior view. Representative ratio images, pseudocolored with low $\mathrm{Ca}^{2+}$ represented by blue, and high $\mathrm{Ca}^{2+}$ represented by yellow/red $(A-C, F-N)$. During somitogenesis, $\mathrm{Ca}^{2+}$ transients are identified as a local short-lived increase in intracellular $\mathrm{Ca}^{2+}$ levels. A region of interest (ROI) is noted by a dashed circle highlighting a representative $\mathrm{Ca}^{2+}$ transient $(\mathrm{A}-\mathrm{C})$. In the $\mathrm{ROI}$ from time $0 \mathrm{~s}$ to time $15 \mathrm{~s}$, an increase in $\mathrm{Ca}^{2+}$ levels is observed (B) that subsides by time $30 \mathrm{~s}(C)$. The number of transients as a function of developmental age (D). Table depicting the average number of $\mathrm{Ca}^{2+}$ transients per hour from 6 to 12 somite stage for each treatment (E). Representative ratio images of 5 somite stage $(F), 7$ somite $(G)$ and 10 somite stage $(H)$ wt embryos taken from Video S1. Representative ratio images of 5 somite (I), 7 somite $(J)$ and 10 somite stage (K) rgs3 MOsa injected embryo taken from Video S2. Representative ratio images of 5 somite (L), 7 somite stage (M) and 10 somite stage (N) wnt5b MO injected embryo taken from Video S4. Red arrowheads indicate large $\mathrm{Ca}^{2+}$ transients in rgs3 morphant embryos $(\mathrm{I}-\mathrm{K})$ that are not observed in wt $(\mathrm{F}-\mathrm{H})$ or wnt5b morphant embryos $(\mathrm{L}-\mathrm{N})$. doi:10.1371/journal.pgen.1001020.g005

initiating transients leading to responses in neighboring cells, resulting in larger areas of increased $\mathrm{Ca}^{2+}$ release (Figure 5I-5K, Video S2). These large and robust transients are not observed in wt embryos (Figure 5F-5H, Video S1) or in morphant embryos co-injected with rgs3 RNA (Video S3). The same dramatic increase in both the frequency of release and amplitude is observed in lateral views as well (Figure S2E, S2F, S2G, and S2K). The change in $\mathrm{Ca}^{2+}$ release dynamics in rgs 3 morphants is consistent with a delayed shut-off of $\mathrm{G}$ protein signaling, i.e. normally mediated by the GAP activity of Rgs3. These data indicate that during the segmentation period Rgs3 functions to limit the extent and duration of endogenous $\mathrm{Ca}^{2+}$ release activity.

Previously, we reported reduced $\mathrm{Ca}^{2+}$ release in blastula stage Wnt5b (pipetail) genetic mutants [24]. When compared to wild-type embryos, wnt $5 b$ morphant embryos show a statistically reduced number of $\mathrm{Ca}^{2+}$ transients, averaging 1.3 per hour $(\mathrm{n}=2)$ during the segmentation period (Figure 5D-5E, 5L, and 5M; Video S4). A similar decrease in frequency is also observed in a lateral view (Figure S2H, S2I, S2J, S2K). The size and duration of $\mathrm{Ca}^{2+}$ transients observed in wnt $5 b$ morphants are comparable to wt embryos (Video S4). In order to determine if the increased frequency of $\mathrm{Ca}^{2+}$ transients associated with rgs 3 knockdown is dependent upon wnt $5 b$ signaling, we simultaneously knocked down wnt $5 b$ and rgs3. Embryos co-injected with wnt $5 b$ MO and rgs $3 \mathrm{MO}$ and imaged during the segmentation period show a statistically reduced number of $\mathrm{Ca}^{2+}$ transients, 1.8 per hour $(\mathrm{n}=5)$ (Figure 5D-5E). The reduced $\mathrm{Ca}^{2+}$ release in the double knockdown is not significantly different than wnt5b single knockdown, demonstrating that the rgs 3 morphant phenotype is dependent upon Wnt signaling. 


\section{rgs3 and wnt5b interaction}

Studies have shown that increased $\mathrm{Wnt} / \mathrm{Fz}$ signaling leads to degradation of Dvl [53-55]. In addition Drosophila genetics places active $G$ protein signaling upstream of Dvl [32]. Therefore, it seemed essential to determine whether Rgs3 plays a role in modulation of Dvl levels. In the absence of an antibody to evaluate Dvl levels, we generated a myc-tagged (MT) form of zebrafish Dvl2 that is readily detected by western blot after injection into embryos (Figure 6A). We find that wnt5b coexpression reduced Dvl-MT levels (Figure 6A). Reduction of Rgs3 function, via MO knockdown, also leads to decreased DvlMT levels. These data demonstrate that endogenous Rgs3 functions in the non-canonical Wnt pathway upstream of Dvl, thereby functioning to modulate the duration and robustness of Wnt5 signaling. To further explore interaction between Rgs3 and Wnt5b, we defined a low dose for wnt $5 b$ MO which results in a mild A-P extension phenotype and determined whether rgs3 enhances or suppresses the wnt $5 b$ gene knockdown defects. Phenotypes were evaluated by morphology (Figure 6B, 6E, 6H, and $6 \mathrm{~K}$ ) and molecular markers, krox20 and myoD (Figure $6 \mathrm{C}-6 \mathrm{D}$, 6F, 6G, 6I, 6J, 6L, and 6M). Compared to wt (Figure 6B-6D), low dose wnt5b MO (2 ng) results in a mild phenotype (Figure $6 \mathrm{E}-$ $6 \mathrm{G})$. We next defined a sub-phenotypic dose for rgs3 MOsa $(0.8 \mathrm{ng})$, which produced a phenotype (Figure $6 \mathrm{H}-6 \mathrm{~J}$ ) indistinguishable from wt (Figure 6B-6D). Individual injection of low dose $r g s 3 \mathrm{MOsa}$ or wnt5b MO did not induce any severe defects (Figure 6N). However, wnt5b MO (2 ng) combined with rgs 3 MOsa $(0.8 \mathrm{ng})$ resulted in a $92 \%$ penetrance of severe defects (Figure $6 \mathrm{~K}-6 \mathrm{~N}$ ). Our $\mathrm{Ca}^{2+}$ imaging implicated Rgs3 function in limiting the extent and duration of endogenous $\mathrm{Ca}^{2+}$ release activity and that this was dependent upon Wnt5. However, in the presence of low level Wnt5 activity (low-dose MO), partial knockdown of rgs3 could lead to discordant changes in the frequency and amplitude of $\mathrm{Ca}^{2+}$ release result in the dramatic phenotypic penetrance and severity.

\section{Discussion}

These results provide new evidence for an essential role of Rgs3 in modulating the duration of Wnt5b signaling. We show that Rgs3 is necessary for proper gastrulation and somite patterning during zebrafish development. These actions of Rgs3 require its ability to interact with and accelerate the rate of GTP hydrolysis by $\mathrm{G}$ proteins, as revealed by studies employing an Rgs 3 mutant defective in these activities. We describe endogenous $\mathrm{Ca}^{2+}$ release dynamics during somitogenesis. The frequency of $\mathrm{Ca}^{2+}$ transients as well as the observation of sustained $\mathrm{Ca}^{2+}$ activity in the trunk and tail region are consistent with previous reports of $\mathrm{Ca}^{2+}$ activity during zebrafish somitogenesis $[12,51,52,56]$. Of particular significance is the dramatic change in frequency of endogenous $\mathrm{Ca}^{2+}$ release upon rgs3 knockdown.

RGS proteins were identified as negative regulators of $G$ protein signaling in the mid 1990s $[57,58]$ and the role of $\mathrm{G}$ proteins in Wnt/Ca ${ }^{2+}$ signaling was first demonstrated in 1997 [22]. Subsequent reports further implicated $G$ proteins in canonical Wnt signaling $[31,59,60]$. Heterotrimeric $G$ protein activation and inactivation are tightly regulated to provide precise control of the amplitude and duration of $G$ protein signaling. Receptorstimulated GTP binding activates $\mathrm{G}$ proteins, while their intrinsic GTPase activity functions to terminate signaling. RGS proteins by definition accelerate this GTPase activity. Over-expression studies in cell culture [61] and in Xenopus embryos [62] have indicated that specific RGS proteins are sufficient to regulate canonical Wnt signaling. Although $\mathrm{G}$ protein signaling is required for normal cell movement during zebrafish gastrulation [11], the role of RGS proteins in noncanonical Wnt signaling has not been investigated. Our current study identifies a member of the RGS protein family that has a direct impact on frequency and amplitude of Wnt5b signaling. We find that Rgs3 activity is sufficient to modulate wont $5 b$ induced $\mathrm{Ca}^{2+}$ release and this ability requires GAP activity consistent with the known role of $\mathrm{G}$ proteins in the activation of Wnt signal transduction pathways $[5,63,64]$. We report the key novel finding that knockdown of Rgs3 results in increased frequency and amplitude of $\mathrm{Ca}^{2+}$ release that this dramatic impact on $\mathrm{Ca}^{2+}$ dynamics in the somites is dependent upon Wnt5 supporting that $\mathrm{Wnt} / \mathrm{Ca}^{2+}$ signaling activity is an in vivo target of RGS proteins. Moreover, rgs 3 demonstrates a complex genetic interaction with wnt5b. rgs3 is expressed in and near wnt $5 b$ expressing tissues and we find that combined low doses of wnt $5 b$ $\mathrm{MO}$ and rgs3 MOsa result in a large penetrance of severe somite defects which is not observed during their individual knockdown. Our data suggest that both the frequency and amplitude of wont $5 b$ signaling must be tightly regulated to result in correct cell movement and somite patterning.

Wnt5b modulates both transient $\mathrm{Ca}^{2+}$ release activity in small populations of cells, as well as, sustained activity in a large region of cells [16]. While the transient release correlates with limiting $\beta$ catenin activity $[17,26]$, we hypothesize that the sustained activity correlates with polarized cell movement, for example in convergence-extension movements during gastrulation or neural and vascular outgrowth [16]. This concept is supported by vascular outgrowth defects in pipetail genetic mutants [65] as well as the observation of a reduction in sustained $\mathrm{Ca}^{2+}$ activity at the somite boundaries (data not shown). It is of interest to determine if interactions between $r g s 3$ and wnt $5 b$ influence directed vascular outgrowth.

Modulation of $\mathrm{G}$ protein signaling (impacting frequency as well as duration) is likely to influence directed cell migration, vascular development as well as numerous other developmental processes [66-68]. Our findings clearly justify the need for further investigations into the role of RGS proteins in this process and other interactions between Rgs3 and Wnt signaling to provide new insights into their mechanistic role in directed cell movement and disease. Our loss of function analysis coupled with rescue and in vivo physiological analysis in whole embryos has provided compelling functional insight into the developmental role of RGS proteins in the Wnt signaling network.

\section{Materials and Methods}

\section{Zebrafish}

Adults were maintained in a 14-hour light / 10-hour dark cycle at $28^{\circ} \mathrm{C}$. Embryos were collected from natural pairwise matings and staged by hours post fertilization (hpf) at $28.5^{\circ} \mathrm{C}$ and morphological criteria described in Kimmel et al. [50,69].

\section{Zebrafish rgs3 point mutants}

rgs3 (clone IBD5096) was isolated in an expression screen in zebrafish [41] and generously provided by Dr. I. Dawid. MOresistant $r g s 3$ was generated by RT-PCR and directionally cloned $\left(5^{\prime}-3^{\prime}\right)$ into the pCS2+, pCS2+ myc or pCS2+ Flag expression vector. The Quick Change II site-directed mutagenesis kit (Stratagene) was used to generate an Asparagine (N) to Alanine (A) substitution at amino acid 109 which is located in the RGS domain of Rgs3. Synthetic RNA was then in vitro transcribed using SP6 RNA polymerase and the mMessage mMachine system (Ambion). 
A
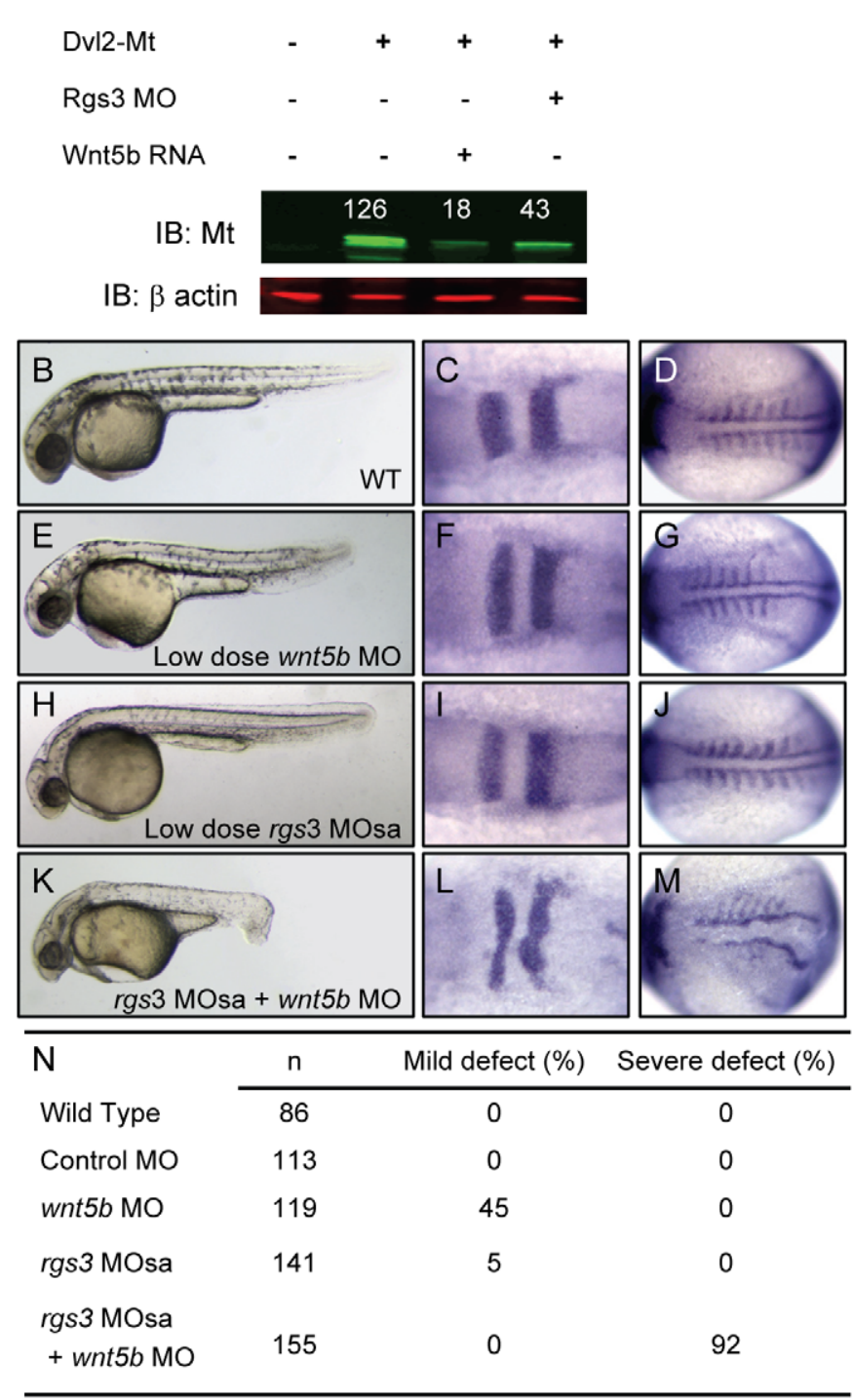

Figure 6. rgs3 interacts with the Wnt-signaling network. Western analysis demonstrates that Dvl-MT levels are reduced by both wnt5b overexpression as well as Rgs3 knockdown (A). Odyssey Infrared Imaging System was used to quantify the relative intensity of Dvl-MT normalized to the $\beta$ actin loading control and shown as numbers above the IB:MT bands. Low doses of rgs 3 and wnt5b MOs were used to test genetic interaction (B-N). Phenotypes were characterized by morphology $(B, E, H, K, N)$ and the molecular markers krox2O $(C, F, I, L)$ and myoD $(D, G, J, M)$. Lateral images of $34 \mathrm{hpf}$ wt (B), low dose wnt5b MO (E), low dose rgs3 MOsa (H), and wnt5b MO+rgs3 MOsa (K) injected embryos. Dorsal images of 13hpf wt (C,D), low dose wnt5b MO (F,G), low dose rgs3 MOsa (I,J), and wnt5b MO+rgs3 MOsa (L,M) injected embryos. Low dose wnt5b MO+rgs3 MOsa resulted in a $92 \%$ penetrance of severe defects which were not observed with low dose wnt5b MO or low dose rgs3 MOsa alone (N).

doi:10.1371/journal.pgen.1001020.g006

\section{Micro-injections}

Antisense morpholino oligonucleotides (MO) were designed to target the 5'-UTR/ATG (rgs3 $\mathrm{MO}$ and rgs3 $\mathrm{MOb}$ ) to inhibit translation and an intron-exon junction in the RGS domain $\operatorname{rggs}_{3} 3$ MOsa) to alter splicing. As a control rgs3 MOmm (5 bp mismatch in lowercase letters) was designed (Gene-Tools):

rgs3 MO 5'-AGTCGGTTCTTCATGTCTTTGGCGC-3', rgs3 MOb 5'-TGTCGGAGAAATCGACGATAGTGTG-3', rgs3 MOsa 5'-CGAGTCGATCTGATGAGGGAGAGAG-3'. rgs3 MOmm 5'-TCaCGcAGAAATCGtCGATtGTcTG-3' .

MOs (5-20ng) were pressure-injected into one cell-stage embryos. For low-dose knockdown, 0.8ng rgs3 MOsa and/or $2 \mathrm{ng}$ wnt5b MO [65] were injected into one cell zebrafish embryos. Control rgs $3 \mathrm{MOmm}$ did not produce any phenotype at $25 \mathrm{ng}$. For rescue, in vitro-transcribed MO-resistant rgs3 (500 pg) was coinjected with $20 \mathrm{ng}$ rgs $3 \mathrm{MO}$. Injected embryos were characterized by morphological and molecular analysis.

\section{Whole-mount in situ hybridization}

Embryos were fixed overnight in $4 \%$ paraformaldehyde and dechorionated. Single label WMISH was performed as previously described [24,70], using digoxigenen (Dig)-labeled or dinitrophenyl (DNP)-labeled antisense and sense RNA probes. Detection was carried out using BM purple (Roche Applied Science). Double label WMISH was performed as previously described [71], using both Dig and DNP-labeled antisense probes. Purple color was developed with AP-conjugated anti-Dig and BM purple (Roche Applied Science), and red color was developed with AP- 
conjugated anti-DNP and INT RED (Roche Applied Science). Reactions were stopped in phosphate-buffered saline (PBS). Embryos were mounted on bridged coverslips and photographed using a Zeiss Stemi M13 Stereoscope and an Axiocam digital camera.

\section{Western analysis}

To compare levels of MT-Rgs3 and mutant MT-Rgs3, embryos were injected with either myc-rgs 3 or $m y c_{\text {-rgs }} 3^{(\mathcal{N 1 0 9 A )}}(750 \mathrm{pg})$. To investigate Rgs3's impact on Dvl, C-terminal myc tagged zebrafish $d v l 2(300 \mathrm{pg})$ was injected alone, with $r g s 3$ MOsa (5ng), with wnt $5 b$ (250pg), and with both rgs3 MOsa (5ng) and wot5b (250pg). Injected Embryos were allowed to develop to the appropriate stage (5 hpf and $24 \mathrm{hpf}$ ) before incubating in lysis buffer $(20 \mu \mathrm{M}$ Tris, $100 \mu \mathrm{M} \mathrm{NaCl}, 1 \mu \mathrm{M}$ EDTA, $5 \%$ Triton, .5\%SDS, 10\% Leupeptin and $0.1 \mu \mathrm{M}$ PMSF) at room temperature for 3 minutes. Embryos were then disrupted using a pestle, centrifuged at 13,000 rpm for 10 minutes at $4^{\circ} \mathrm{C}$ and the clear supernatant containing whole zebrafish protein was collected. Approximately $10 \mu \mathrm{g}$ of protein was loaded in each well and separated with SDS-PAGE gel electrophoresis. Proteins were transferred onto nitrocellulose membrane (Li-Cor) and incubated with the following primary antibodies: mouse anti-myc (1:2,000; Cell Signaling Technology) and rabbit anti- $\beta$ actin (1:2,000; Sigma), and then incubated with the following secondary antibodies: IRDye800 anti-mouse (1:20,000; Li-Cor) and IRDye680 anti-rabbit (1:20,000; Li-Cor). The signal was visualized using the Odyssey Infrared Imaging System (Li-Cor).

\section{Immunohistochemistry}

Embryos injected with either myc-rgs3 or $m y c-r g s 3^{(\mathcal{N 1 0 9 A})}(200 \mathrm{pg})$ were fixed $1-3 \mathrm{hrs}$ in $4 \% \mathrm{PFA} / 1 \times \mathrm{PBS}$ at sphere/dome stage. Mouse anti-myc antibody (1:1,500; Cell Signaling Technology), followed by goat-anti-mouse Alexa488 conjugated secondary antibody (1:400; Molecular Probes) was used to detect the rgs3 products. Nuclei were identified with $5 \mu \mathrm{M}$ TO-PRO-3 (Molecular Probes). Embryos were mounted in an animal pole orientation in bridged coverslips and optically sectioned using two-channel imaging on a scanning laser confocal microscope, Leica TCS SP2. Wide-field fluorescence and bright-field images from a Zeiss Stemi M13 Bio Stereoscope were photographed using Axiovision (Zeiss) software and an Axiocam 5000 camera. Images were merged using Adobe Photoshop CS.

\section{Intracellular calcium $\left(\mathrm{Ca}^{2+}\right)$ imaging}

The ratiometric $\mathrm{Ca}^{2+}$-sensing dye Fura-2 or Bis-Fura-2 (Molecular Probes) was injected into 1-cell zebrafish embryos. The excitation spectra are different between $\mathrm{Ca}^{2+}$ bound Fura-2 $(340-\mathrm{nm})$ and $\mathrm{Ca}^{2+}$ free $(380-\mathrm{nm})$ forms. By taking the ratio of the fluorescence intensity at these wavelengths an estimate of intracellular-free $\mathrm{Ca}^{2+}$ can be derived. To stimulate Wnt signaling, in vitro transcribed wnt5b RNA (400 pg) was co-injected with Fura2 at the one cell stage. $r g s 3$ or $r g s 3^{\mathrm{N} 109 \mathrm{~A}}$ RNA (400 pg) was unilaterally injected at the 16 -cell stage mixed with dextranconjugated Texas Red ( $\mathrm{TxR}$ ) lineage tracer. TxR distribution was determined by collecting a reference exposure at 540-nm excitation. For cellular blastoderm stage imaging, embryos were oriented in a lateral position in a glass-bottomed dish on a Zeiss axiovert epifluorescence microscope. Image pairs at 340 and 380$\mathrm{nm}$ excitation wavelengths (510-nm emission) were collected at 15second intervals. Each imaging session collected 300 image pairs. The ratio image, a pixel by pixel match of both excitation wavelengths, is calculated by computer software (RatioTool, Inovision). The sequence of ratio images was processed and the
$\mathrm{Ca}^{2+}$ fluxes (transients) were determined by a subtractive analog patterned after $[72,73]$ and described in $[13,43]$. The ratio image $\left(340 \mathrm{~nm}, \mathrm{Ca}^{2+}\right.$-saturated and $380 \mathrm{~nm}, \mathrm{Ca}^{2+}$-free) imported for publication is encoded in 8 bits and converted to pseudocolor with low ratio $\left(\right.$ low $\mathrm{Ca}^{2+}$ ) represented by blue and high ratio $\left(\right.$ high $\mathrm{Ca}^{2+}$ ) represented by yellow/red.

For somite imaging, 2-6 somite stage embryos were oriented in low melt agarose $(0.4 \%)$ in a dorsal or lateral orientation. Time courses collected images pairs until 12-15 somite stage at 15second intervals (Approximately 1000 images pairs). Image pairs were converted to ratio images as described above. Sequential ratio images were manually analyzed for changes in $\mathrm{Ca}^{2+}$ transients. Somite stage $\mathrm{Ca}^{2+}$ transients were defined as a localized increase in $\mathrm{Ca}^{2+}$ which persists no longer than thirty seconds.

\section{Statistical analysis}

Calculations for MO rescue experiments were made using the Fisher's exact test and the two-tailed p-value was reported. Calculations for analysis of somite stage $\mathrm{Ca}^{2+}$ transients in morphant embryos were made using One-Way Analysis of Variance (one-way ANOVA) with Tukey HSD test p-values reported.

\section{Supporting Information}

Figure S1 rgs3 expression is adjacent and overlapping with wnt5b, related to Figure 1. Temporal and spatial expression of $r g s 3$ compared to wnt5b in zebrafish development. Whole Mount In Situ Hybridization was utilized to compare the spatial expression of went5b to rgs3. WMISH of $14 \mathrm{hpf}(\mathrm{A}-\mathrm{D})$ and $24 \mathrm{hpf}(\mathrm{E}-\mathrm{F}) \mathrm{Wt}$ embryos. Lateral (A-C and $\mathrm{E})$ and dorsal $(\mathrm{D}$ and $\mathrm{F})$ views illustrate that $\operatorname{rgs}_{s} 3$ is expressed in the developing somites and posterior tail (A-E). Co localization of went $5 b$ and $r g s 3$, determined by double label WMISH with wnt $5 b$ (red) and $r g s 3$ (blue), shows adjacent and overlapping expression domains around Kupffer's vesicle $(\mathbf{C})$ and in the tailbud (D). Double label WMISH with rgs3 (blue) and engrailed1 (red) highlight that rgs3 is expressed in the midbrain/ hindbrain boundary (E). Sense probes (negative control) gave no specific hybridization signal.

Found at: doi:10.1371/journal.pgen.1001020.s001 (1.19 MB TIF)

Figure S2 rgs3 impacts segmentation stage calcium dynamics, related to Figure 5. Zebrafish embryos injected with Fura-2 oriented in a lateral posterior view (A) with a focus on the developing somites and tail (boxed region). Ratio images, pseudocolored to represent low $\mathrm{Ca}^{2+}$ as blue and high $\mathrm{Ca}^{2+}$ as yellow/red (B-J). Representative ratio images of 6 somite stage (B, $\mathrm{E}$ and $\mathrm{H}), 8$ somite stage $(\mathrm{C}, \mathrm{F}$, and $\mathrm{I})$ and 10 somite stage $(\mathrm{D}, \mathrm{G}$ and $\mathrm{J}$ ) embryos. Arrowheads indicate large $\mathrm{Ca} 2+$ transients in rgs3 morphant embryos $(\mathrm{E}-\mathrm{G})$ that are not observed in Wt $(\mathrm{B}-\mathrm{D})$ or wnt5b morphant embryos $(\mathrm{H}-\mathrm{J})$. The number of $\mathrm{Ca}^{2+}$ transients per hour observed in embryos oriented in a lateral posterior view from 6 to 12 somite stage is represented function of developmental age is represented graphically $(\mathrm{K})$.

Found at: doi:10.1371/journal.pgen.1001020.s002 (2.07 MB TIF)

Table S1 Rescue efficiency of rgs 3 knockdown, related to Figure 2.

Found at: doi:10.1371/journal.pgen.1001020.s003 (0.04 MB DOC)

Video S1 $\mathrm{Wt}, \mathrm{Ca}^{2+}$ dynamics during zebrafish somitogenesis, related to Figure 5. Time-lapse movie (Wt zebrafish embryo oriented in a dorsal posterior view) consisting of pseudocolored ratio images derived from image pairs (340 and 380-nm excitation 
wavelengths) collected in 15-second intervals over a two hour period with low $\mathrm{Ca}^{2+}$ represented by blue and high $\mathrm{Ca}^{2+}$ represented by yellow/red.

Found at: doi:10.1371/journal.pgen.1001020.s004 (2.58 MB AVI)

Video S2 rgs3 morphant, $\mathrm{Ca}^{2+}$ dynamics during zebrafish somitogenesis, related to Figure 5 Time-lapse movie (rgs3 morphant zebrafish embryo oriented in a dorsal posterior view) consisting of pseudocolored ratio images derived from image pairs (340 and 380-nm excitation wavelengths) collected in 15-second intervals over a two hour period with low $\mathrm{Ca}^{2+}$ represented by blue and high $\mathrm{Ca}^{2+}$ represented by yellow/red.

Found at: doi:10.1371/journal.pgen.1001020.s005 (2.58 MB AVI)

Video S3 rgs3 morphant rescued with rgs 3 RNA, $\mathrm{Ca}^{2+}$ dynamics during zebrafish somitogenesis, related to Figure 5. Time-lapse movie (rgs3 morphant rescued with rgs3 RNA zebrafish embryo oriented in a dorsal posterior view) consisting of pseudocolored ratio images derived from image pairs (340 and 380-nm excitation wavelengths) collected in 15-second intervals over a two hour

\section{References}

1. Cadigan KM, Nusse R (1997) Wnt signaling: a common theme in animal development. Genes Dev 11: 3286-305.

2. Kestler HA, Kuhl M (2008) From individual Wnt pathways towards a Wnt signalling network. Philos Trans R Soc Lond B Biol Sci 363: 1333-47.

3. Widelitz R (2005) Wnt signaling through canonical and non-canonical pathways: recent progress. Growth Factors 23: 111-6.

4. Willert K, Nusse R (1998) Beta-catenin: a key mediator of Wnt signaling. Curr Opin Genet Dev 8: 95-102.

5. Kohn AD, Moon RT (2005) Wnt and calcium signaling: beta-cateninindependent pathways. Cell Calcium 38: 439-46.

6. Cadigan KM, Liu YI (2006) Wnt signaling: complexity at the surface. J Cell Sci 119: 395-402.

7. Dale TC (1998) Signal transduction by the Wnt family of ligands. Biochem J 329(Pt 2): 209-23.

8. Kuhl M, Sheldahl LC, Park M, Miller JR, Moon RT (2000) The Wnt/Ca2+ pathway: a new vertebrate Wnt signaling pathway takes shape. Trends Genet 16: 279-83.

9. Heisenberg CP, Solnica-Krezel L (2008) Back and forth between cell fate specification and movement during vertebrate gastrulation. Curr Opin Genet Dev 18: 311-6.

10. Sepich DS, Myers DC, Short R, Topczewski J, Marlow F, et al. (2000) Role of the zebrafish trilobite locus in gastrulation movements of convergence and extension. Genesis 27: 159-73.

11. Lin F, Chen S, Sepich DS, Panizzi JR, Clendenon SG, et al. (2009) Galpha12/ 13 regulate epiboly by inhibiting E-cadherin activity and modulating the actin cytoskeleton. J Cell Biol 184: 909-21.

12. Webb SE, Miller AL (2000) Calcium signalling during zebrafish embryonic development. Bioessays 22: 113-23.

13. Slusarski DC, Corces VG (2000) Calcium imaging in cell-cell signaling. Methods Mol Biol 135: 253-61.

14. Slusarski DC, Pelegri F (2007) Calcium signaling in vertebrate embryonic patterning and morphogenesis. Dev Biol 307: 1-13.

15. Slusarski DC, Yang-Snyder J, Busa WB, Moon RT (1997) Modulation of embryonic intracellular Ca2+ signaling by Wnt-5A. Dev Biol 182: 114-20.

16. Freisinger GM, Schneider I, Westfall TA, Slusarski DC (2008) Calcium dynamics integrated into signalling pathways that influence vertebrate axial patterning. Philos Trans R Soc Lond B Biol Sci 363: 1377-85.

17. Schneider I, Houston DW, Rebagliati MR, Slusarski DC (2008) Calcium fluxes in dorsal forerunner cells antagonize beta-catenin and alter left-right patterning. Development 135: 75-84.

18. Lyman Gingerich J, Westfall TA, Slusarski DC, Pelegri F (2005) hecate, a zebrafish maternal effect gene, affects dorsal organizer induction and intracellular calcium transient frequency. Dev Biol 286: 427-39.

19. Reinhard E, Yokoe H, Niebling KR, Allbritton NL, Kuhn MA, et al. (1995) Localized calcium signals in early zebrafish development. Dev Biol 170: 50-61.

20. Gilland E, Miller AL, Karplus E, Baker R, Webb SE (1999) Imaging of multicellular large-scale rhythmic calcium waves during zebrafish gastrulation. Proc Natl Acad Sci U S A 96: 157-61.

21. Webb SE, Miller AL (2003) Imaging intercellular calcium waves during late epiboly in intact zebrafish embryos. Zygote 11: 175-82.

22. Slusarski DC, Corces VG, Moon RT (1997) Interaction of Wnt and a Frizzled homologue triggers G-protein-linked phosphatidylinositol signalling. Nature 390: 410-3.

23. Westfall DJ (1997) Managed indemnity insurance-a clear choice for health plan sponsors. Empl Benefits J 22: 26-8. period with low $\mathrm{Ca}^{2+}$ represented by blue and high $\mathrm{Ca}^{2+}$ represented by yellow/red.

Found at: doi:10.1371/journal.pgen.1001020.s006 (1.23 MB AVI)

Video S4 wnt5b morphant, $\mathrm{Ca}^{2+}$ dynamics during zebrafish somitogenesis, related to Figure 5. Time-lapse movie (wnt5b morphant zebrafish embryo oriented in a dorsal posterior view) consisting of pseudocolored ratio images derived from image pairs (340 and 380-nm excitation wavelengths) collected in 15-second intervals over a two hour period with low $\mathrm{Ca}^{2+}$ represented by blue and high $\mathrm{Ca}^{2+}$ represented by yellow/red. Double label WMISH with rgs3 (blue) and engrailed1 (red) highlight that rgs3 is expressed in the midbrain/hindbrain boundary $(\mathrm{E})$.

Found at: doi:10.1371/journal.pgen.1001020.s007 (2.58 MB AVI)

\section{Author Contributions}

Conceived and designed the experiments: DCS. Performed the experiments: CMF DCS. Analyzed the data: CMF DCS. Contributed reagents/ materials/analysis tools: RAF. Wrote the paper: CMF DCS.

24. Westfall TA, Brimeyer R, Twedt J, Gladon J, Olberding A, et al. (2003) Wnt-5/ pipetail functions in vertebrate axis formation as a negative regulator of Wnt/ beta-catenin activity. J Cell Biol 162: 889-98.

25. Holloway BA, Gomez de la Torre Canny S, Ye Y, Slusarski DC, Freisinger CM, et al. (2009) A novel role for MAPKAPK2 in morphogenesis during zebrafish development. PLoS Genet 5: e1000413. doi:10.1371/journal.pgen.1000413.

26. Westfall TA, Hjertos B, Slusarski DC (2003) Requirement for intracellular calcium modulation in zebrafish dorsal-ventral patterning. Dev Biol 259: 380-91

27. Wodarz A, Nusse R (1998) Mechanisms of Wnt signaling in development. Annu Rev Cell Dev Biol 14: 59-88.

28. Malbon CC (2004) Frizzleds: new members of the superfamily of G-proteincoupled receptors. Front Biosci 9: 1048-58.

29. Fredriksson R, Lagerstrom MC, Lundin LG, Schioth HB (2003) The G-proteincoupled receptors in the human genome form five main families. Phylogenetic analysis, paralogon groups, and fingerprints. Mol Pharmacol 63: 1256-72.

30. Wang HY, Liu T, Malbon CC (2006) Structure-function analysis of Frizzleds. Cell Signal 18: 934-41.

31. Ahumada A, Slusarski DC, Liu X, Moon RT, Malbon CC, et al. (2002) Signaling of rat Frizzled-2 through phosphodiesterase and cyclic GMP. Science 298: $2006-10$.

32. Katanaev VL, Ponzielli R, Semeriva M, Tomlinson A (2005) Trimeric G protein-dependent frizzled signaling in Drosophila. Cell 120: 111-22.

33. Gilman AG (1987) G proteins: transducers of receptor-generated signals. Annu Rev Biochem 56: 615-49.

34. Ross EM, Wilkie TM (2000) GTPase-activating proteins for heterotrimeric G proteins: regulators of $\mathrm{G}$ protein signaling (RGS) and RGS-like proteins. Annu Rev Biochem 69: 795-827.

35. Hollinger S, Hepler JR (2002) Cellular regulation of RGS proteins: modulators and integrators of $\mathrm{G}$ protein signaling. Pharmacol Rev 54: 527-59.

36. De Vries L, Zheng B, Fischer T, Elenko E, Farquhar MG (2000) The regulator of G protein signaling family. Annu Rev Pharmacol Toxicol 40: 235-71.

37. Siderovski DP, Willard FS (2005) The GAPs, GEFs, and GDIs of heterotrimeric G-protein alpha subunits. Int J Biol Sci 1: 51-66.

38. Watson N, Linder ME, Druey KM, Kehrl JH, Blumer KJ (1996) RGS family members: GTPase-activating proteins for heterotrimeric G-protein alphasubunits. Nature 383: 172-5.

39. Hepler JR, Berman DM, Gilman AG, Kozasa T (1997) RGS4 and GAIP are GTPase-activating proteins for $\mathrm{Gq}$ alpha and block activation of phospholipase C beta by gamma-thio-GTP-Gq alpha. Proc Natl Acad Sci U S A 94: 428-32.

40. Kozasa $\mathrm{T}$ (1998) [Regulation of $\mathrm{G}$ protein-mediated signaling pathways by RGS proteins]. Seikagaku 70: 1418-22.

41. Kudoh T, Tsang M, Hukriede NA, Chen X, Dedekian M, et al. (2001) A gene expression screen in zebrafish embryogenesis. Genome Res 11: 1979-87.

42. Rauch GJ, Hammerschmidt M, Blader P, Schauerte HE, Strahle U, et al. (1997) Wnt 5 is required for tail formation in the zebrafish embryo. Cold Spring Harb Symp Quant Biol 62: 227-34.

43. Freisinger CM, Houston DW, Slusarski DC (2008) Image analysis of calcium release dynamics. Methods Mol Biol 468: 145-56.

44. Chang DC, Meng C (1995) A Localized Elevation of Cytosolic Free Calcium is Associated with Cytokinesis in the Zebrafish Embryo. The Journal of Cell Biology 131: 1539-1545.

45. Lechleiter J, Gira S, Peralta E, Clapham D (1991) Spiral Calcium Wave Propagation and Annihilation in Xenopus laevis Oocytes. Science 252: 123-126. 
46. Srinivasa SP, Watson N, Overton MC, Blumer KJ (1998) Mechanism of RGS4, a GTPase-activating protein for $\mathrm{G}$ protein alpha subunits. J Biol Chem 273: 1529-33.

47. Tesmer JJ, Berman DM, Gilman AG, Sprang SR (1997) Structure of RGS4 bound to AlF4-activated G(i alphal): stabilization of the transition state for GTP hydrolysis. Cell 89: 251-61.

48. Natochin M, McEntaffer RL, Artemyev NO (1998) Mutational analysis of the Asn residue essential for RGS protein binding to G-proteins. J Biol Chem 273: 6731-5.

49. Morcos PA (2000) Gene switching: analyzing a broad range of mutations using steric block antisense oligonucleotides. Methods Enzymol 313: 174-89.

50. Kimmel CB, Ballard WW, Kimmel SR, Ullmann B, Schilling TF (1995) Stages of embryonic development of the zebrafish. Dev Dyn 203: 253-310.

51. Creton R, Speksnijder JE, Jaffe LF (1998) Patterns of free calcium in zebrafish embryos. J Cell Sci 111(Pt 12): 1613-22.

52. Webb SE, Miller AL (2006) Ca2+ signaling during vertebrate somitogenesis. Acta Pharmacol Sin 27: 781-90.

53. Gao C, Chen YG. Dishevelled: The hub of Wnt signaling. Cell Signal 22: 717-27.

54. Angers S, Thorpe CJ, Biechele TL, Goldenberg SJ, Zheng N, et al. (2006) The KLHL12-Cullin-3 ubiquitin ligase negatively regulates the Wnt-beta-catenin pathway by targeting Dishevelled for degradation. Nat Cell Biol 8: 348-57.

55. Jung H, Kim HJ, Lee SK, Kim R, Kopachik W, et al. (2009) Negative feedback regulation of Wnt signaling by Gbetagamma-mediated reduction of Dishevelled. Exp Mol Med 41: 695-706.

56. Webb SE, Miller AL (2007) Ca2+ signalling and early embryonic patterning during zebrafish development. Clin Exp Pharmacol Physiol 34: 897-904.

57. Dohlman HG, Apaniesk D, Chen Y, Song J, Nusskern D (1995) Inhibition of Gprotein signaling by dominant gain-of-function mutations in Sst2p, a pheromone desensitization factor in Saccharomyces cerevisiae. Mol Cell Biol 15: 3635-43.

58. Koelle MR, Horvitz HR (1996) EGL-10 regulates G protein signaling in the C. elegans nervous system and shares a conserved domain with many mammalian proteins. Cell 84: 115-25.

59. Liu T, DeCostanzo AJ, Liu X, Wang H, Hallagan S, et al. (2001) G protein signaling from activated rat frizzled-1 to the beta-catenin-Lef-Tcf pathway. Science 292: 1718-22.
60. Liu X, Liu T, Slusarski DC, Yang-Snyder J, Malbon CC, et al. (1999) Activation of a frizzled-2/beta-adrenergic receptor chimera promotes Wnt signaling and differentiation of mouse F9 teratocarcinoma cells via Galphao and Galphat. Proc Natl Acad Sci U S A 96: 14383-8.

61. Feigin ME, Malbon CC (2007) RGS19 regulates Wnt-beta-catenin signaling through inactivation of Galpha(o). J Cell Sci 120: 3404-14.

62. Wu C, Zeng Q Blumer KJ, Muslin AJ (2000) RGS proteins inhibit Xwnt-8 signaling in Xenopus embryonic development. Development 127: 2773-84.

63. Schulte G, Bryja V (2007) The Frizzled family of unconventional G-proteincoupled receptors. Trends Pharmacol Sci 28: 518-25.

64. Force T, Woulfe K, Koch WJ, Kerkela R (2007) Molecular scaffolds regulate bidirectional crosstalk between Wnt and classical seven-transmembrane-domain receptor signaling pathways. Sci STKE 2007: pe41.

65. Cirone P, Lin S, Griesbach HL, Zhang Y, Slusarski DC, et al. (2008) A role for planar cell polarity signaling in angiogenesis. Angiogenesis.

66. Parmalee NL, Kitajewski J (2008) Wnt signaling in angiogenesis. Curr Drug Targets 9: 558-64.

67. Zerlin M, Julius MA, Kitajewski J (2008) Wnt/Frizzled signaling in angiogenesis. Angiogenesis 11: 63-9.

68. Albig AR, Schiemann WP (2005) Identification and characterization of regulator of G protein signaling 4 (RGS4) as a novel inhibitor of tubulogenesis: RGS4 inhibits mitogen-activated protein kinases and vascular endothelial growth factor signaling. Mol Biol Cell 16: 609-25.

69. Westerfield M (1995) The zebrafish book: a guide for the laboratory use of zebrafish (Danio rerio) (Eugene, OR, M. Westerfield).

70. Thisse C, Thisse B, Schilling TF, Postlethwait JH (1993) Structure of the zebrafish snaill gene and its expression in wild-type, spadetail and no tail mutant embryos. Development 119: 1203-15.

71. Long S, Rebagliati M (2002) Sensitive two-color whole-mount in situ hybridizations using digoxygenin- and dinitrophenol-labeled RNA probes. Biotechniques 32: 494, 496, 498 passim.

72. Chang DC, Meng C (1995) A localized elevation of cytosolic free calcium is associated with cytokinesis in the zebrafish embryo. J Cell Biol 131: 1539-45.

73. Lechleiter J, Girard S, Peralta E, Clapham D (1991) Spiral calcium wave propagation and annihilation in Xenopus laevis oocytes. Science 252: 123-6. 